\title{
Infrapatellar fat pads participate in the development of knee osteoarthritis in obese patients via the activation of the NF-kB signaling pathway
}

\author{
LIJUN DUAN $^{1}$, YUAN MA ${ }^{1}$, YONGGUI WANG ${ }^{1}$, JIJUN LIU $^{1}$, \\ ZEEN TAN $^{1}$, QI WU ${ }^{1}$, YONGGANG WU ${ }^{1}$ and XING $\mathrm{YU}^{2}$ \\ ${ }^{1}$ Department of Orthopedics, Bayannaoer City Hospital, Bayannaoer, Inner Mongolia 015000; \\ ${ }^{2}$ Department of Orthopedics, Dongzhimen Hospital, Beijing University of Chinese Medicine, Beijing 100700, P.R. China
}

Received September 12, 2019; Accepted August 28, 2020

DOI: $10.3892 / \mathrm{ijmm} .2020 .4739$

\begin{abstract}
The aim of the present study was to assess the activation of nuclear factor- $\kappa \mathrm{B}(\mathrm{NF}-\kappa \mathrm{B})$ in the infrapatellar fat pads (IPFPs) of obese patients with knee osteoarthritis (KOA). For this purpose, 32 patients (22 obese patients with KOA and 10 patients with KOA with a healthy weight) treated with total knee arthroplasty (TKA) were selected. The expression levels of pro-inflammatory cytokines and adipocytokines, and the activation of NF- $\kappa \mathrm{B}$ were detected in both the cases and controls by enzyme-linked immunosorbent assay (ELISA), western blot analysis and immunohistochemistry where appropriate. SPSS 18.0 software was used for statistical analysis to determine the correlation between obesity and the detected cytokine levels. It was found that in patients with $\mathrm{KOA}$, the expression of leptin in the synovial fluid positively correlated with body mass index $(\mathrm{BMI} ; \mathrm{P}<0.05)$, and the
\end{abstract}

Correspondence to: Dr Xing Yu, Department of Orthopedics, Dongzhimen Hospital, Beijing University of Chinese Medicine, 5 Haiyuncang Street, Dongcheng, Beijing 100700, P.R. China

E-mail: yuxingbucm@sina.com

Dr Yonggang Wu, Department of Orthopedics, Bayannaoer City Hospital, 98 Wulanbuhe Street, Lin He, Bayannaoer, Inner Mongolia 015000, P.R. China

E-mail: wuyonggang555@163.com

Abbreviations: KOA, knee osteoarthritis; IPFP, infrapatellar fat pad; OA, osteoarthritis; BMI, body mass index; IL, interleukin; TNF, tumor necrosis factor; PGE2, prostaglandin E2; SPFP, supra-fat pad; NF- $\kappa \mathrm{B}$, nuclear factor kappa B; TKA, total knee arthroplasty; HE, hematoxylin-eosin; ELISA, enzyme-linked immunosorbent assay; BCA, bicinchoninic acid; SDS-PAGE, sodium dodecyl sulfate polyacrylamide gel electrophoresis; PVDF, polyvinylidene fluoride; IF, immunofluorescence; DAPI, 4',6-diamidino-2-phenylindole; VLDL, very low-density lipoprotein; ESR, erythrocyte sedimentation rate; VEGF, vascular endothelial growth factor

Key words: knee osteoarthritis, obesity, infrapatellar fat pad, nuclear factor- $\kappa \mathrm{B}$ signaling pathway expression of interleukin (IL)-6 in serum significantly correlated with the IL-1 $\beta$, leptin and tumor necrosis factor (TNF)- $\alpha$ levels $(\mathrm{P}<0.05)$. Furthermore, the expression of inflammatory cytokines and adipocytokines in IPFPs differed significantly between the obese and non-obese patients with KOA $(\mathrm{P}<0.05)$. By evaluating the expression of IKK $\beta$ and $\mathrm{I} \kappa \mathrm{B} \alpha$ and the nuclear translocation ability of $\mathrm{p}-\mathrm{p} 65$, it was concluded that $\mathrm{NF}-\kappa \mathrm{B}$ signaling was activated to a higher degree in the IPFP tissues of obese patients with KOA than in those of patients with KOA with a healthy weight. On the whole, the findings of the present study suggested that the $\mathrm{NF}-\kappa \mathrm{B}$ signaling pathway was activated and that there were changes in the expression in levels of inflammatory cytokines and adipocytokines in the IPFP tissues of obese patients with KOA.

\section{Introduction}

Obesity is accompanied by chronic low-grade inflammation that can induce knee osteoarthritis (KOA) $(1,2)$. In patients with KOA, the infrapatellar fat pads (IPFP) produce numerous inflammatory cytokines and adipocytokines, which, in turn, trigger inflammation and become a source of pain (3). With increases in the aging population and the proportion of obese patients, the incidence of osteoarthritis (OA) is on the rise (4). It has been demonstrated that individuals with a higher body mass index (BMI) are at a greater risk of developing KOA, and that being overweight can cause the release of various cellular inflammatory factors, including interleukin (IL)-6, IL-1 $\beta$ and tumor necrosis factor (TNF)- $\alpha$, and can also induce the production of cartilage degradation factors (5). Moreover, metabolic disorders caused by obesity and metabolic abnormalities may lead to the release of adipocytokines and the occurrence of inflammation $(3,6)$.

Adipose tissue contains a number of different cell types that can produce a large number of diverse cytokines. In healthy or non-obese individuals, the levels of protein expression, cell proliferation, differentiation and apoptosis are maintained in a balanced and stable state (7). When body weight increases, pro-inflammatory macrophages in the body and immune cells such as $\mathrm{CD} 8^{+} \mathrm{T}$ cells, mast cells and $\mathrm{B}$ cells enter adipose tissue, leading to a shift towards low-grade 
inflammation (8). In addition, fat cells begin to produce cytokines, known as adipocytokines, and these changes also affect other tissues, thereby leading to the development of multiple diseases (9). It has been demonstrated that obesity has a marked impact on cartilage metabolism and that increased glycosaminoglycan (GAG) release is considered as a hallmark of cartilage destruction (10). It has been proven that the level of free GAG produced in cartilage tissue is positively associated with BMI (10). Moreover, it has been demonstrated that obese patients are more likely to express IL-1 $\beta$, IL-6 and IL-18 than lean individuals (11). These factors may exert marked effects on obesity-related diseases, including atherosclerosis and diabetes (12-14). IL-1 $\beta$ is a major catabolic factor in cartilage degradation that is highly induced in patients with OA and is reportedly associated with BMI. Moreover, IL-18 has been reported to induce prostaglandin E2 (PGE2), which is an important inflammatory mediator in the synovium, and IL- 6 has been reported to be involved in bone remodeling (13).

The IPFP is an intra-articular adipose tissue that has received much attention in recent years. From an anatomical point of view, there are a variety of adipose tissues in the joints, including the IPFP and a supra-fat pad (SPFP), consisting of a quadriceps fat pad and a prefemoral fat pad, which are located above the tibia and behind the supraorbital sac. The IPFP has recently been described as a repository of intra-articular cytokines and a source of inflammatory cells, such as leukocytes and $\mathrm{CD} 1^{+}$cells (15). The IPFP releases higher amounts of inflammatory factors than autologous subcutaneous adipose tissue in patients with KOA. Additionally, the size of the IPFP and the level of TNF- $\alpha$ are positively associated with the BMI of patients with OA (16-18). Similarly, in high-fat diet-fed mice, increases in weight and IPFP volume are positively correlated with OA development (19). It has been demonstrated that OA synovitis may be associated with inflammatory factors released by the IPFP on the anterior surface of the synovial membrane (20). Therefore, the IPFP may exert paracrine functions on other joint tissues in OA, paritcularly adjacent synovial membranes.

The nuclear factor $-\kappa \mathrm{B}(\mathrm{NF}-\kappa \mathrm{B})$ signaling pathway is one of the most significant pathways involved in the treatment and intervention of arthritis and related inflammatory diseases (21). A previous study found that the $N F-\kappa B$ signaling pathway was activated by chondrocytes stimulated with IL-1 $\beta$ (22). In OA-affected rat cartilage tissue, $\mathrm{NF}-\kappa \mathrm{B}$ $\mathrm{p}$-p65, as well as the $\mathrm{NF}-\kappa \mathrm{B}$ signaling molecules, IKK $\alpha$, IKK $\beta$ and phosphorylated $\mathrm{I} \kappa \mathrm{B} \alpha$, have been shown to be upregulated (23). However, whether the NF- $\kappa \mathrm{B}$ signaling pathway is activated in different parts of infraorbital fat pad tissue in KOA requires further exploration. Therefore, in the present study, different adipose tissues were collected to explore the activation of the NF- $\mathrm{NB}$ pathway, and differences in the expression of inflammatory cytokines and adipocytokines between obese and non-obese patients with KOA. Furthermore, experiments were also conducted to investigate the correlation between the release of related cytokines in serum and the joint fluid of patients with BMI. The present study aimed to focus on the IPFP and explore both the role and the molecular mechanisms of the IPFP in obese and non-obese patients with KOA.

\section{Materials and methods}

Human samples. At total of 32 patients with OA who underwent total knee arthroplasty (TKA) from September, 2017 to July, 2018 at Bayannaoer Hospital, China were recruited in the present study. These included 22 obese patients with KOA with a $\mathrm{BMI} \geq 24\left(28.33 \pm 3.87, \mathrm{~kg} / \mathrm{m}^{2}\right)$ and $10 \mathrm{KOA}$ patients with a healthy weight (average BMI of $22.58 \pm 0.80, \mathrm{~kg} / \mathrm{m}^{2}$ ). Males accounted for $31.25 \%(10 / 32)$ of the patients, and females accounted for $68.75 \%(22 / 32)$ of the patients. Subjects with secondary, traumatic and/or rheumatoid arthritis, combined with severe immune diseases were excluded. Furthermore, subcutaneous adipose tissue I, IPFP tissue (near the synovial side II and near the patellar tendon side IV) and suprapatellar fat body III tissues were collected from obese and non-obese patients with KOA. The present study was approved by the Ethics Committee of Bayannaoer Hospital and was performed in accordance with the Helsinki Declaration. All participants signed informed consent forms for the extraction of knee joint fluid and the voluntary donation of IPFP specimens.

Hematoxylin and eosin $(H \& E)$ staining. IPFP tissues collected from the patients with KOA were dehydrated, frozen, sliced and stained with hematoxylin (Baiaolaibo Company) and eosin (Sinopharm Group Co., Ltd.). Subsequently, morphological differences in the tissues of obese and lean patients with KOA were observed using an Olympus fluorescence microscope (Olympus Corporation).

Cytokine measurement. Serum and knee joint fluid was collected and stored at $-80^{\circ} \mathrm{C}$ for serum cytokine analysis. The levels of pro-inflammatory cytokines (IL-1 $\beta$, IL-6 and TNF- $\alpha$ ) were analyzed by enzyme-linked immunosorbent assay (ELISA) kits (Santa Cruz Biotechnology, Inc.) according to the manufacturer's instructions.

$R T$ - $q P C R$. RT-qPCR was used to examine the expression of IL-1 $\beta$, IL-6, TNF- $\alpha$, leptin, adiponectin, visfatin, peroxisome proliferator-activated receptor (PPAR) $\gamma, \mathrm{I} \kappa \mathrm{B} \alpha$ and NF- $\kappa \mathrm{B}$ p65 at the mRNA level. According to the manufacturer's instructions, TRIzol reagent (Invitrogen; Thermo Fisher Scientific, Inc.) was used to extract total RNA. Following reverse transcription (RevertAid First Strand cDNA Synthesis kit, \#K1622, Thermo Fisher Scientific, Inc.), SYBR-Green Master Mix (Life Technologies; Thermo Fisher Scientific, Inc.) was used for the quantitative analysis of gene expression. Amplification, which involved a denaturation step, and quantification were repeated for 40 cycles $\left(95^{\circ} \mathrm{C}\right.$ for $15 \mathrm{sec}$ and $60^{\circ} \mathrm{C}$ for $\left.60 \mathrm{sec}\right)$. The primer sequences are listed in Table SI. The relative gene expression levels were calculated using the $2^{-\Delta \Delta \mathrm{Cq}}$ method (24) and are presented as the fold change in gene transcript levels. GAPDH was used as the internal control for RT-qPCR for normalization.

Western blot analysis. The expression of target proteins was detected by western blot analysis. In the present study, the total protein was extracted with RIPA lysis buffer (CW2334S, CoWin Bioscience) from cartilage tissues, and a bicinchoninic acid (BCA) protein assay kit (Beyotime Institute of Biotechnology, Inc.) was used to measure the total protein concentration of the samples. Total protein $(20 \mu \mathrm{g})$ 
was loaded per well and then separated by sodium dodecyl sulfate polyacrylamide gel electrophoresis (SDS-PAGE, with a $12 \%$ separating gel and a $4 \%$ stacking gel) and transferred onto polyvinylidene fluoride (PVDF) membranes. The membranes were blocked with $3 \%$ non-fat milk for $1.5 \mathrm{~h}$ at room temperature, and then incubated with primary antibodies against IL-1 $\beta$ (Proteintech, 16806-1-AP, 1:2,000), IL-6 (Elabscience, E-AB-30095, 1:1,000) and TNF- $\alpha$ (Elabscience, E-AB-40015, 1:2,000), leptin (Abcam, ab16227, 1:4,000), adiponectin (Abcam, ab22554, 1:2,000), visfatin (Abcam, ab236874, 1:3,000), PPAR $\gamma$ (Proteintech, 16643-1-AP, 1:800), IKK $\beta$ (Abcam, ab124957, 1:1,000), IкB $\alpha$ (Abcam, ab32518, 1:800), p-NF-кB p65 (Servicebio, GB11142-1, 1:500), NF-кB p65 (Servicebio, GB11997, 1:500) and $\beta$-tubulin (Proteintech, 10068-1-AP, 1:2,000) at $4^{\circ} \mathrm{C}$ overnight. Following incubation with an HRP-conjugated secondary antibody (Servicebio, GB23303, 1:3,000) for $1.5 \mathrm{~h}$ at room temperature, the protein bands were visualized using an enhanced chemiluminescence detection system (Tanon-5200, Shanghai Tanon Science and Technology Ltd.). The results were further analyzed using Image-Pro Plus 6.0 software (Media Cybernetics, Inc.).

Immunofluorescence (IF). Paraffin-embedded adipose tissue sections were dewaxed, washed 3 times with PBS, and blocked with 5\% goat serum. The samples were incubated with a p-p65 primary antibody (1:150, GB11142-1, Servicebio, Inc.), diluted with PBST at $4^{\circ} \mathrm{C}$ overnight, washed and then incubated with secondary antibody (Alexa Fluor 594-conjugated goat anti-rabbit IgG, AS039, ABclonal) at $37^{\circ} \mathrm{C}$ for $60 \mathrm{~min}$. After washing with PBS, 4',6-diamidino-2-phenylindole (DAPI, Boster, AR1176) was used for nuclear staining $\left(37^{\circ} \mathrm{C}\right.$ for $15 \mathrm{~min})$. Finally, the tissues were imaged using a confocal laser microcope (Nikon DS-U3; Nikon Corporation) after being sealed with an antifade mounting medium (Beyotime, P0126).

Statistical analysis. All acquired data were analyzed with Microsoft Excel and Statistical Package for Social Science software 18.0 (SPSS, Inc.). Welch's t-test was used to assess differences in age, clinical characteristics, and the levels of cytokines determined by ELISA between the cases and controls. Pearson's Chi-squared test was utilized to examine differences in sex between the cases and controls. Correlations were analyzed by Spearman's rank correlation test, with $\mathrm{r}$ values representing the correlation coefficient. A P-value (two-tailed) $<0.05$ was considered to indicate a statistically significant difference.

\section{Results}

General demographic data and indicator levels in cases and controls. A total of 22 obese patients with KOA (mean age, $63.77 \pm 6.60$ years) and 10 patients with KOA with a healthy weight (mean age, 68.60 \pm 4.74 years) were included in the present study (Table I). A significant difference in age $(\mathrm{P}=0.047)$ was found between the cases and controls, although no differences in sex $(\mathrm{P}=0.123)$ were observed between the groups. Clinical data were collected from the patients and significant differences were found in BMI $(\mathrm{P}<0.001)$, very low-density lipoprotein (VLDL) levels $(\mathrm{P}=0.039)$ and erythrocyte sedimentation rates (ESRs, $\mathrm{P}=0.043$ ) between the obese and non-obese patients.
Table I. Demographics and clinical characteristics of the cases and controls.

\begin{tabular}{lccc}
\hline Variable & Cases $(\mathrm{n}=22)$ & Controls $(\mathrm{n}=10)$ & P-value \\
\hline Age (years) & $63.77 \pm 6.60$ & $68.60 \pm 4.74$ & $0.047^{\mathrm{a}, \mathrm{c}}$ \\
Sex & & & $0.123^{\mathrm{b}}$ \\
Male & 5 & 5 & \\
Female & 17 & 5 & \\
BMI $\left(\mathrm{kg} / \mathrm{m}^{2}\right)$ & $28.33 \pm 3.87$ & $22.58 \pm 0.80$ & $<0.001^{\mathrm{a}, \mathrm{c}}$ \\
HDL $(\mathrm{mmol} / \mathrm{l})$ & $1.33 \pm 0.30$ & $1.29 \pm 0.46$ & $0.798^{\mathrm{a}}$ \\
LDL $(\mathrm{mmol} / \mathrm{l})$ & $2.88 \pm 1.32$ & $3.32 \pm 0.80$ & $0.362^{\mathrm{a}}$ \\
VLDL $(\mathrm{mmol} / \mathrm{l})$ & $1.02 \pm 1.46$ & $0.29 \pm 0.10$ & $0.039^{\mathrm{a}, \mathrm{c}}$ \\
CRP $(\mathrm{mg} / \mathrm{l})$ & $3.20 \pm 3.25$ & $2.00 \pm 1.11$ & $0.296^{\mathrm{a}}$ \\
ESR $(\mathrm{mm} / \mathrm{h})$ & $24.40 \pm 19.57$ & $10.67 \pm 7.73$ & $0.043^{\mathrm{a}, \mathrm{c}}$ \\
\hline
\end{tabular}

BMI, body mass index; HDL, high density lipoprotein; LDL, low density lipoprotein; VLDL, very low-density lipoprotein; CRP, C-reactive protein; ESR, erythrocyte sedimentation rate. ${ }^{\text {aP }}$-values calculated by the t-test. ${ }^{\mathrm{b}} \mathrm{P}$-values calculated by Pearson's Chi-squared test. ${ }^{\mathrm{c}} \mathrm{P}<0.05$, statistically significant difference.

Differences in ELISA indexes were also analyzed between the cases and controls (Table II), and it was concluded that the expression levels of leptin in serum $(\mathrm{P}=0.033)$ and IL-6 in the synovia $(\mathrm{P}=0.039)$ differed significantly between the obese and lean patients with KOA.

Differences in clinical characteristics and ELISA indexes between the male and female patients with KOA were also analyzed (Table SII); however, no significant differences were found; this suggested that sex was not a factor that affected clinical data or the expression of inflammatory cytokines and adipocytokines in obese patients with KOA.

Correlation analysis. Correlations between ELISA indexes (IL-6, IL-1 $\beta$, leptin and TNF- $\alpha$ levels in serum and joint fluid) and BMI were analyzed using SPSS software and Spearman's correlation analysis (Table III), and the results suggested that the expression of leptin in the synovia significantly correlated with BMI ( $\mathrm{r}=0.058, \mathrm{P}=0.003)$.

The correlations between age, clinical data and ELISA indexes were further analyzed in all the study participants (Table SIII). Only BMI was found to correlate with age $(\mathrm{r}=-0.445, \mathrm{P}=0.011)$. The correlations between the patient clinical characteristics and the ELISA indexes were then analyzed (Table IV) and it was found that the expression of IL- $1 \beta$ in serum positively correlated with the VLDL level. In serum, the expression of IL-6 significantly correlated with the levels of IL-1 $\beta$, leptin and TNF- $\alpha$. In joint fluid, the expression of IL-1 $\beta$ positively correlated with the level of TNF- $\alpha(\mathrm{P}<0.05)$.

Observation of tissue morphological characteristics. H\&E staining was used to compare the morphological characteristics of the sub-patellar fat pad in obese and non-obese patients with KOA. Two samples of each group were detected and the results revealed that there was no marked differences in the morphology of fat cells between the non-obese and obese group (Fig. S1). 
Table II. Differences in cytokine levels determined by ELISA between the cases and controls.

\begin{tabular}{lcccc}
\hline & Cytokines $(\mathrm{pg} / \mathrm{ml})$ & Cases $(\mathrm{n}=22)$ & Controls $(\mathrm{n}=10)$ & \\
\hline Serum & & & & \\
& IL-6 & & & \\
& IL-1 $\beta$ & $116.86 \pm 143.43$ & $121.11 \pm 154.50$ & 0.950 \\
& Leptin & $154.50 \pm 144.22$ & $133.38 \pm 85.34$ & 0.737 \\
& TNF- $\alpha$ & $92,953.26 \pm 70,742.61$ & $8,538.02 \pm 2,279.42$ & $0.033^{\mathrm{a}}$ \\
Synovia & & $269.64 \pm 252.16$ & $155.78 \pm 96.38$ & 0.101 \\
& IL-6 & & $381.03 \pm 269.15$ & $0.039^{\mathrm{a}}$ \\
& IL-1 $\beta$ & $164.39 \pm 201.44$ & $2.93 \pm 4.54$ & 0.373 \\
& Leptin & $5.12 \pm 5.41$ & $3,042.15 \pm 1,540.94$ & 0.007 \\
\hline
\end{tabular}

P-values were calculated using a t-test. ${ }^{\mathrm{a}} \mathrm{P}<0.05$, statistically significant difference.

Table III. Correlations between ELISA indexes and BMI in all patients with KOA.

\begin{tabular}{|c|c|c|c|c|c|c|c|c|}
\hline \multirow[b]{2}{*}{ Location } & \multicolumn{2}{|c|}{ IL-6 } & \multicolumn{2}{|c|}{ IL-1 $\beta$} & \multicolumn{2}{|c|}{ Leptin } & \multicolumn{2}{|c|}{$\mathrm{TNF}-\alpha$} \\
\hline & $\mathrm{r}$ & P-value & $\mathrm{r}$ & P-value & $\mathrm{r}$ & P-value & $\mathrm{r}$ & $\mathrm{P}$-value \\
\hline Serum & 0.258 & 0.185 & 0.113 & 0.568 & -0.084 & 0.672 & 0.279 & 0.150 \\
\hline Synovia & -0.311 & 0.108 & 0.012 & 0.951 & $0.058^{\mathrm{a}}$ & 0.003 & 0.096 & 0.627 \\
\hline
\end{tabular}

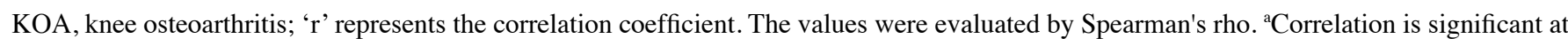
the 0.01 level.

Activation of $N F-\kappa B$ signaling is increased in the IPFP of obese patients with $\mathrm{KOA}$. In the present study, the activation of $\mathrm{NF}-\kappa \mathrm{B}$ in the tissues (I, II, III and IV) of patients with KOA was examined by RT-qPCR and western blot analysis, and the results suggested that in obese patients with KOA, the expression of I $\mathrm{B} \mathrm{B} \alpha$ in IPFP tissues (II and IV) was downregulated compared with that in subcutaneous adipose tissue $(\mathrm{P}<0.05$, Fig. $1 \mathrm{~A}$ and $\mathrm{B})$. It was also found that the expression of $\mathrm{I} \kappa \mathrm{B} \alpha$ in the IPFP of obese patients with KOA was downregulated compared with that in the IPFP in lean patients $(\mathrm{P}<0.05$, Fig. 1C). On the contrary, the expression of IKK $\beta$ and the phosphorylation level of p65 (p-p65/p65) were upregulated in IPFP tissues compared to subcutaneous adipose tissues ( $\mathrm{P}<0.05$; Figs. $2 \mathrm{~A}$, and $3 \mathrm{~A}$ and $\mathrm{B})$ in obese patients with KOA. These expression levels in IPFP tissues were also higher in the obese group than the lean group $(\mathrm{P}<0.05$, Figs. $2 \mathrm{~B}$ and $3 \mathrm{C})$.

To further confirm the activation of the NF- $\kappa \mathrm{B}$ signaling pathway, IF was used to detect changes in the nuclear localization of p-p65 in different tissues of 3 patients with KOA of each group. The results revealed that the p-p65 (red) signals were located in the nuclei in IPFP tissues (II and IV) and the suprapatellar body fat (III) (Fig. 4). Moreover, it was also found that the signal intensity in the IPFP tissues of the obese group was higher than that in IPFP tissues of the lean controls (Fig. 4).

Expression of pro-inflammatory factors is altered in the IPFP and other adipose tissues of obese patients with KOA. The changes in the expression levels of IL-1 $\beta$, IL- 6 and TNF- $\alpha$ in different adipose tissues from patients with KOA were then detected. In subcutaneous adipose tissues (I) and the suprapatellar fat body (III), the expression levels of IL-1 $\beta$, IL-6 and TNF- $\alpha$ did not differ significantly between the lean and obese groups (Fig. 5A and C). However, in IPFP tissues (II and IV), the mRNA expression of levels of related targets were markedly upregulated in the obese group than the lean group $(\mathrm{P}<0.05$, Fig. 5B and D). The results of western blot analysis confirmed that the expression levels of IL-1 $\beta$, IL- 6 and TNF- $\alpha$ in IPFP tissues increased as the body weight increased $(\mathrm{P}<0.05$, Fig. $5 \mathrm{E})$.

Expression of adipocytokines is altered in the IPFP and other adipose tissues of obese patients with KOA. The changes in the expression levels of leptin, adiponectin, visfatin and PPAR $\gamma$ in different adipose tissues from patients with KOA were further verified. No significant differences in expression levels in subcutaneous adipose tissues (I) and suprapatellar fat body (III) were found between the obese and lean patients with KOA (Fig. 6A and C). However, the results also suggested that in IPFP tissues (II and IV), the mRNA expression levels of PPARG and visfatin were decreased, while those of leptin were increased $(\mathrm{P}<0.05$, Fig. $6 \mathrm{~B}$ and $\mathrm{D})$. Furthermore, the protein expression levels of these targets were detected by western blot analysis. The results revealed that in the obese group, the expression of visfatin was significantly lower than that in the controls, whereas that of leptin was upregulated compared to the non-obese group $(\mathrm{P}<0.05$, Fig. $6 \mathrm{E})$. 
Table IV. Correlations between ELISA indexes and clinical indexes in all patients with KOA.

\begin{tabular}{|c|c|c|c|c|c|c|c|c|c|c|c|c|c|}
\hline \multirow[b]{2}{*}{$\mathrm{r}$} & \multirow[b]{2}{*}{ HDL } & \multirow[b]{2}{*}{ LDL } & \multirow[b]{2}{*}{ VLDL } & \multirow[b]{2}{*}{ CRP } & \multirow[b]{2}{*}{ ESR } & \multicolumn{2}{|c|}{ IL-6 } & \multicolumn{2}{|c|}{ IL-1 $\beta$} & \multicolumn{2}{|c|}{ Leptin } & \multicolumn{2}{|c|}{ TNF- $\alpha$} \\
\hline & & & & & & Serum & Synovia & Serum & Synovia & Serum & Synovia & Serum & Synovia \\
\hline HDL & 1.000 & -0.070 & -0.133 & 0.001 & 0.077 & -0.386 & 0.116 & -0.324 & 0.111 & -0.022 & 0.166 & -0.033 & -0.032 \\
\hline LDL & & 1.000 & -0.020 & 0.125 & 0.100 & 0.049 & -0.169 & -0.139 & 0.087 & 0.216 & 0.155 & 0.275 & -0.058 \\
\hline VLDL & & & 1.000 & 0.187 & 0.139 & 0.253 & 0.014 & $0.416^{\mathrm{a}}$ & 0.243 & 0.048 & -0.005 & 0.222 & 0.089 \\
\hline CRP & & & & 1.000 & 0.087 & 0.174 & -0.380 & 0.228 & -0.083 & -0.107 & 0.108 & 0.123 & -0.132 \\
\hline ESR & & & & & 1.000 & -0.092 & -0.182 & 0.049 & 0.274 & -0.035 & 0.193 & 0.068 & 0.116 \\
\hline \multicolumn{14}{|l|}{ IL-6 } \\
\hline Serum & & & & & & 1.000 & 0.002 & $0.466^{\mathrm{a}}$ & -0.222 & $0.401^{\mathrm{a}}$ & -0.167 & $0.562^{\mathrm{b}}$ & 0.009 \\
\hline Synovia & & & & & & & 1.000 & -0.330 & 0.061 & -0.176 & -0.063 & -0.122 & 0.225 \\
\hline \multicolumn{14}{|l|}{ IL-1 $\beta$} \\
\hline Serum & & & & & & & & 1.000 & -0.033 & 0.284 & -0.224 & 0.369 & -0.017 \\
\hline Synovia & & & & & & & & & 1.000 & -0.209 & -0.224 & -0.015 & $0.759^{b}$ \\
\hline \multicolumn{14}{|l|}{ Leptin } \\
\hline Serum & & & & & & & & & 1.000 & -0.099 & 0.330 & -0.175 & \\
\hline Synovia & & & & & & & & & & & 1.000 & -0.099 & -0.186 \\
\hline \multicolumn{14}{|l|}{ TNF- $\alpha$} \\
\hline Serum & & & & & & & & & & & & 1.000 & -0.127 \\
\hline Synovia & & & & & & & & & & & & & 1.000 \\
\hline
\end{tabular}

KOA, knee osteoarthritis; HDL, high density lipoprotein; LDL, low density lipoprotein; VLDL, very low-density lipoprotein; CRP, C-reactive protein; ESR, erythrocyte sedimentation rate. The values were evaluated by Spearman's rho. ' $r$ ' represents the correlation coefficient. ${ }^{\mathrm{a} C o r r e l a-}$

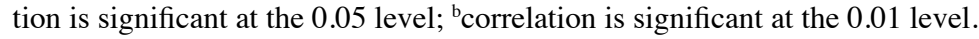

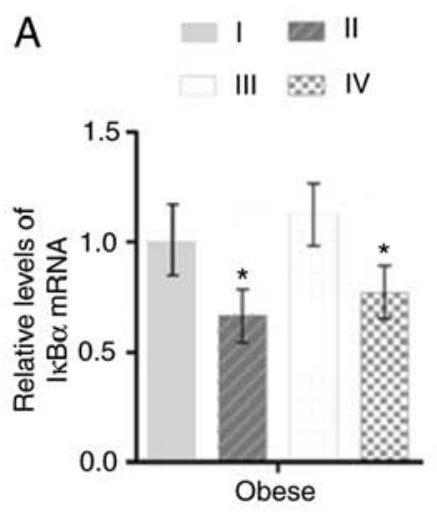

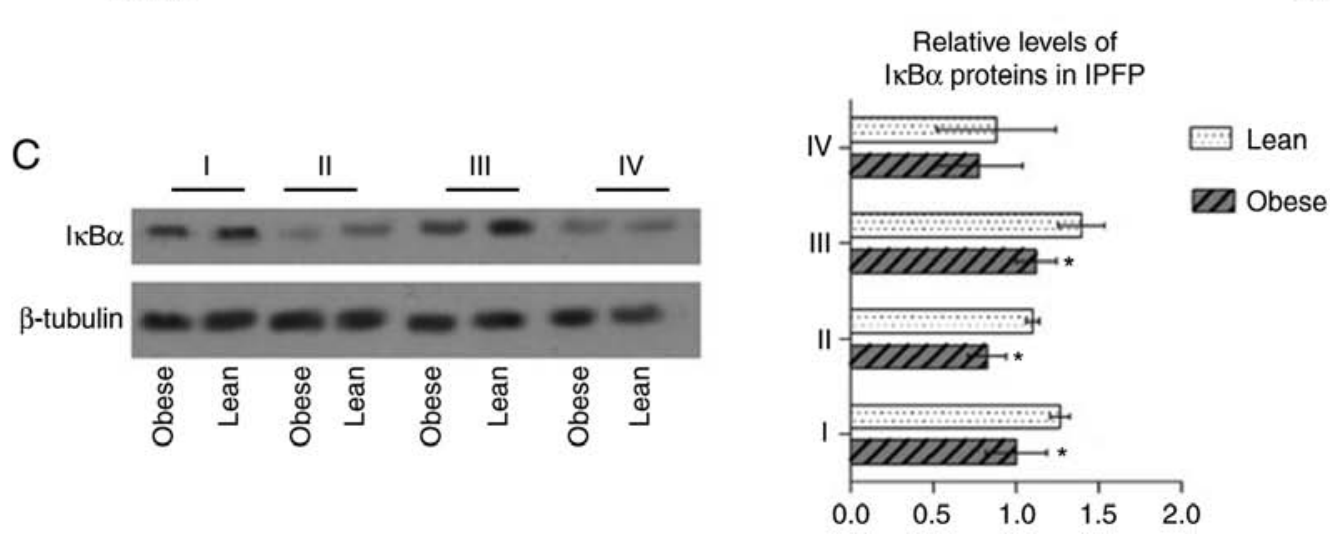
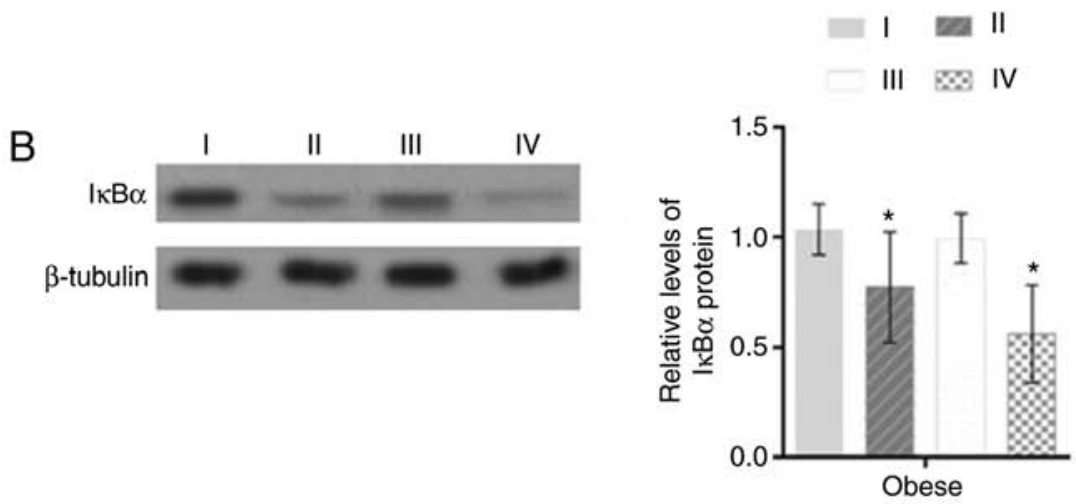

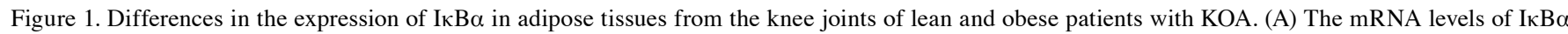

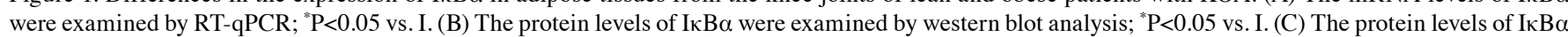
were examined by western blot analysis; * $\mathrm{P}<0.05$ vs. lean patients. KOA, knee osteoarthritis; I, subcutaneous adipose tissue; II, IPFP near the synovial side; III, suprapatellar fat body; IV, near the patellar tendon side. 
A

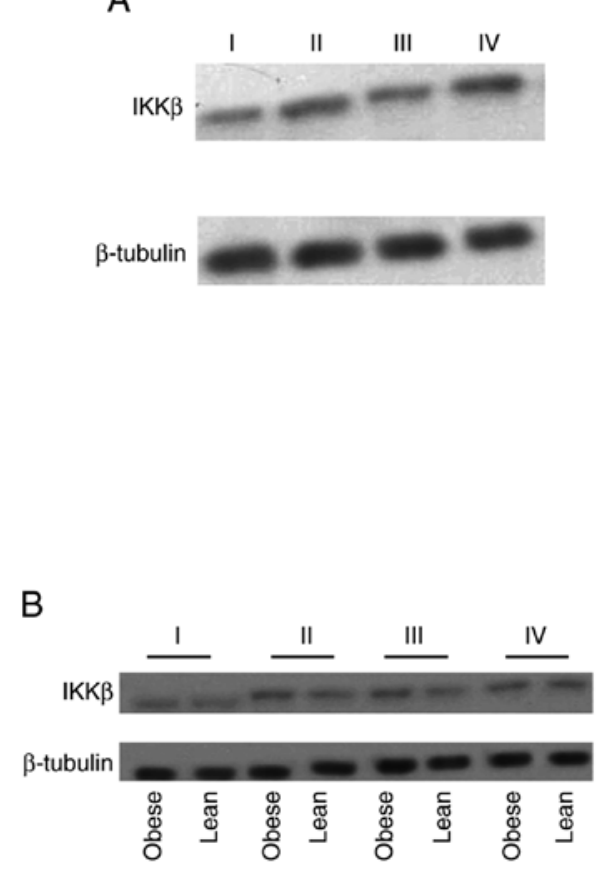

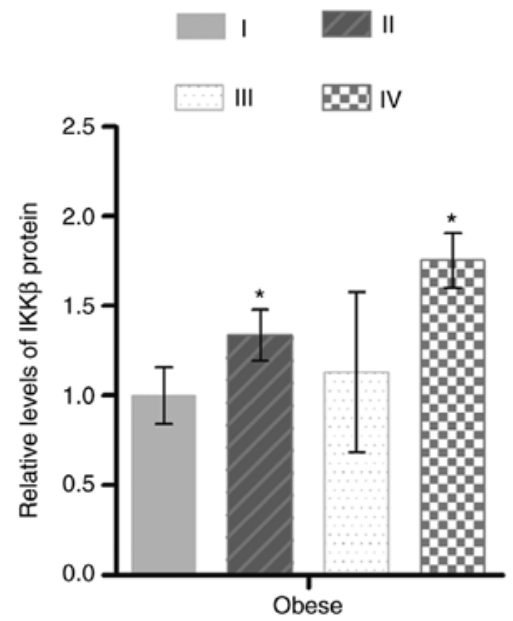

Relative levels of IKK $\beta$ proteins in IPFP

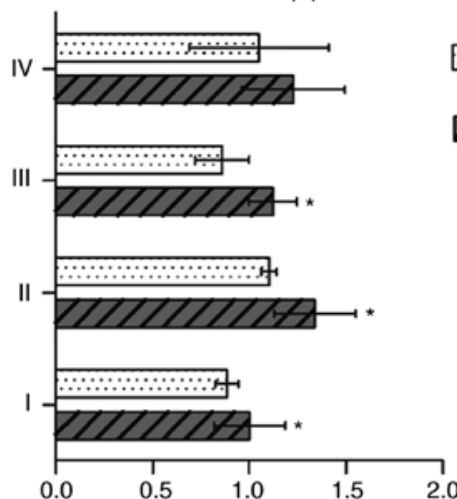

Figure 2. Differences in the expression of IKK $\beta$ in adipose tissues from the knee joints of lean and obese patients with KOA. (A) The protein levels of IKK $\beta$ were examined by western blot analysis; " $\mathrm{P}<0.05$ vs. I. (B) The protein levels of IKK $\beta$ were examined by western blot analysis; " $\mathrm{P}<0.05$ vs. lean patients. KOA, knee osteoarthritis; I, subcutaneous adipose tissue; II, IPFP near the synovial side; III, suprapatellar fat body; IV, near the patellar tendon side.

A

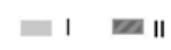

5 III $100 \mathrm{IV}$

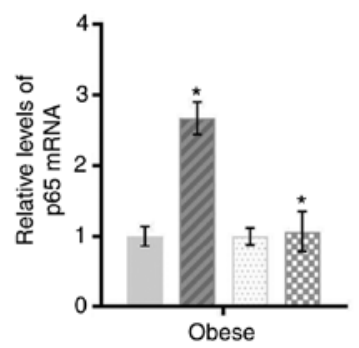

B

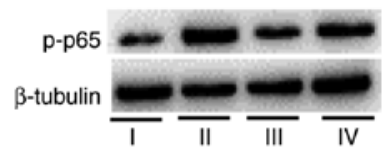

p65

$\beta$-tubulin

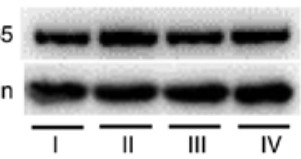

- I m II

$\square$ III $\square$ IV

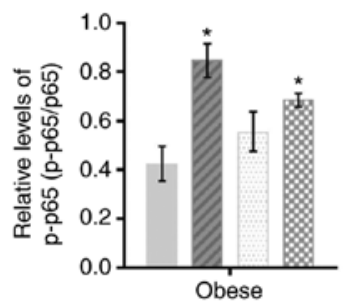

C

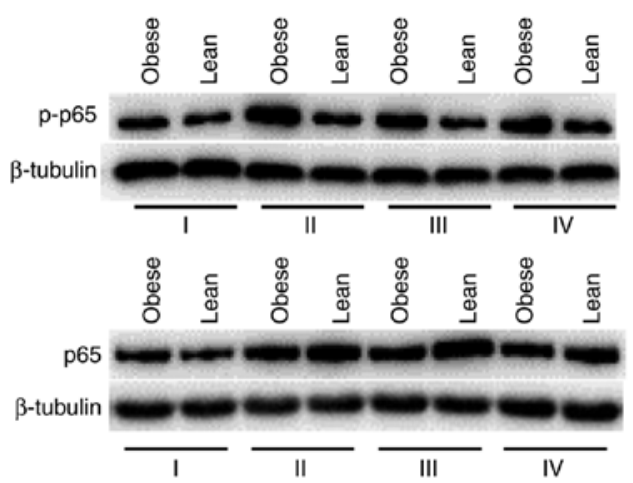

Relative levels of p-p65 (p-p65/p65) in IPFP

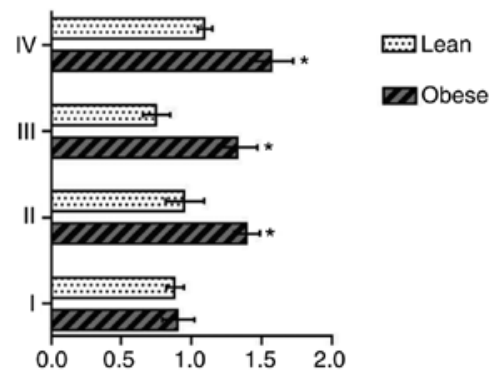

Figure 3. Differences in the expression of p65 in adipose tissues from the knee joints of lean and obese patients with KOA. (A) The mRNA levels of p65 were examined by RT-qPCR; * $\mathrm{P}<0.05$ vs. I. (B) The phosphorylation levels of $\mathrm{p} 65$ (p-p65/p65) were examined by western blot analysis; ${ }^{*} \mathrm{P}<0.05$ vs. I. (C) The phosphorylation levels of p65 (p-p65/p65) were examined by western blot analysis; "P<0.05 vs. lean patients. KOA, knee osteoarthritis; I, subcutaneous adipose tissue; II, IPFP near the synovial side; III, suprapatellar fat body; IV, near the patellar tendon side. 

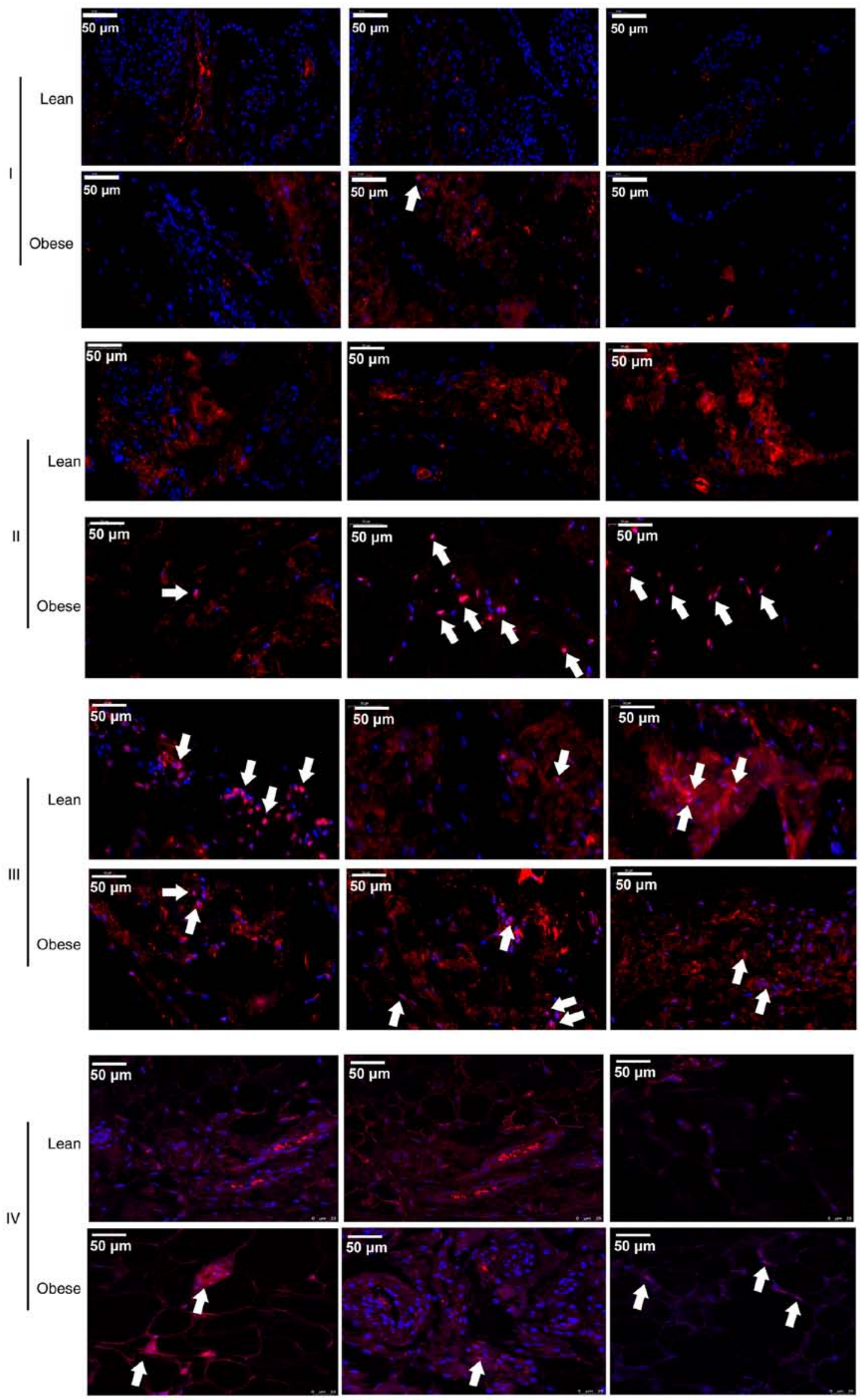

Figure 4. The localization of p-p65 in the IPFP tissue, subcutaneous adipose tissues and suprapatellar fat bodies of 3 patients with KOA from each group (samples from these 3 patients in each group are illustrated in each row, respectively) was detected by immunofluorescence staining. The p-p65 signals were colored in red and the nuclei were colored in blue, and the overlapping expression is merged in purple color and indicated by arrows. KOA, knee osteoarthritis; I, subcutaneous adipose tissue; II, IPFP near the synovial side; III, suprapatellar fat body; IV, near the patellar tendon side. 
A

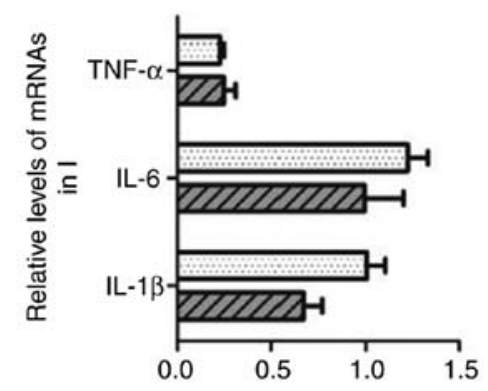

D四 Obese $\square$ Lean

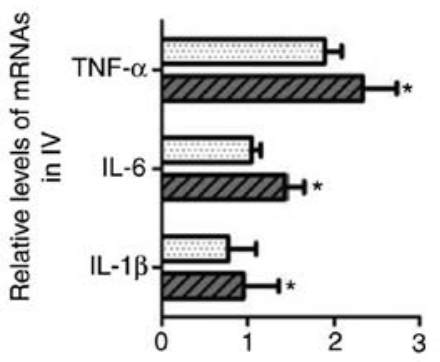

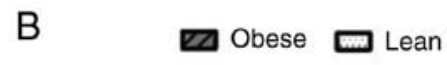

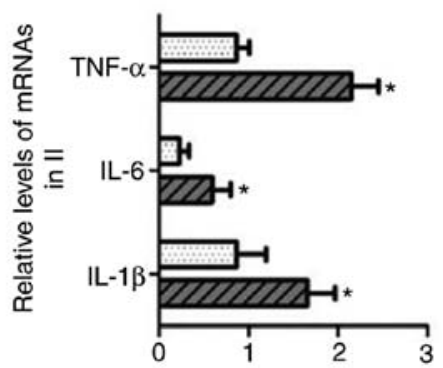

C $\square$ Obese $\square$ Lean

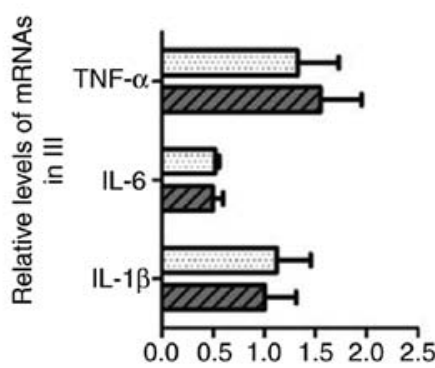

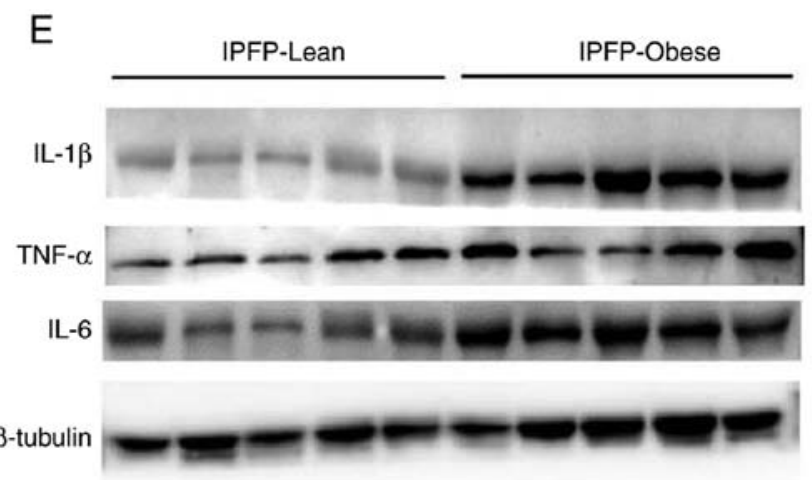

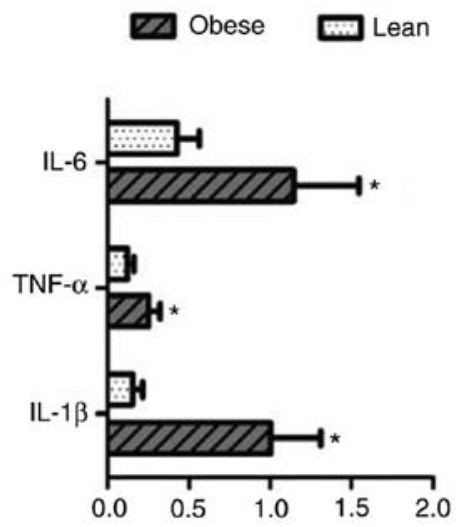

Figure 5. Differences in the expression of IL-1 $\beta$, IL- 6 and TNF- $\alpha$ in adipose tissues from the knee joints of lean and obese patients with KOA. (A-D) The mRNA levels of IL-1 $\beta$, IL- 6 and TNF- $\alpha$ were examined by RT-qPCR; ${ }^{*} \mathrm{P}<0.05$ vs. I. (E) The protein levels of IL-1 $\beta$, IL- 6 and TNF- $\alpha$ were examined by western blot analysis; " $\mathrm{P}<0.05$ vs. lean patients. KOA, knee osteoarthritis; I, subcutaneous adipose tissue; II, IPFP near the synovial side; III, suprapatellar fat body; IV, near the patellar tendon side.

\section{Discussion}

$\mathrm{OA}$ is the most common form of arthritis and is characterized by the loss of cartilage structure. Obesity is a chronic inflammatory condition and is also a high risk factor for OA (25). Obesity increases the incidence of OA, particularly in weight-bearing joints, such as the knee joint. It is generally believed that obesity increases the mechanical load of articular cartilage, leading to joint degeneration $(26,27)$. In the present study, a total of 32 patients with KOA were recruited, including 22 obese patients and 10 patients with normal weight to investigate the molecular mechanisms of obesity as regards the induction of KOA.

Inflammatory factors are known to participate in the regulation of intra-articular inflammatory processes and play a key role in the process of articular cartilage degradation, which is crucial in the pathogenesis of OA (27). In the present study, samples of serum and joint fluid were collected from all patients with KOA and the expression levels of inflammatory factors, such as IL- 6 , IL- $1 \beta$, TNF- $\alpha$, and the pro-inflammatory adipocytokine, leptin, were detected between the obese and non-obese subjects by ELISA. The results indicated that the leptin level in serum and the IL-6 level in the synovia differed significantly between the cases and controls, and that the leptin level positively correlated with BMI. Previous studies have reported that obese individuals are more likely to produce IL-1 $\beta$, IL-6, IL-18 and TNF- $\alpha$ than lean individuals $(28,29)$. Another study demonstrated that IL- $1 \beta$ was highly induced in patients with OA and was associated with BMI (30). In addition, leptin is also believed to play a key role in the development of OA, and the expression level of leptin in serum has been found to be positively associated with OA $(31,32)$.

Recent studies have demonstrated that the IPFP, a source of inflammatory cytokines, mediates the progression of KOA 

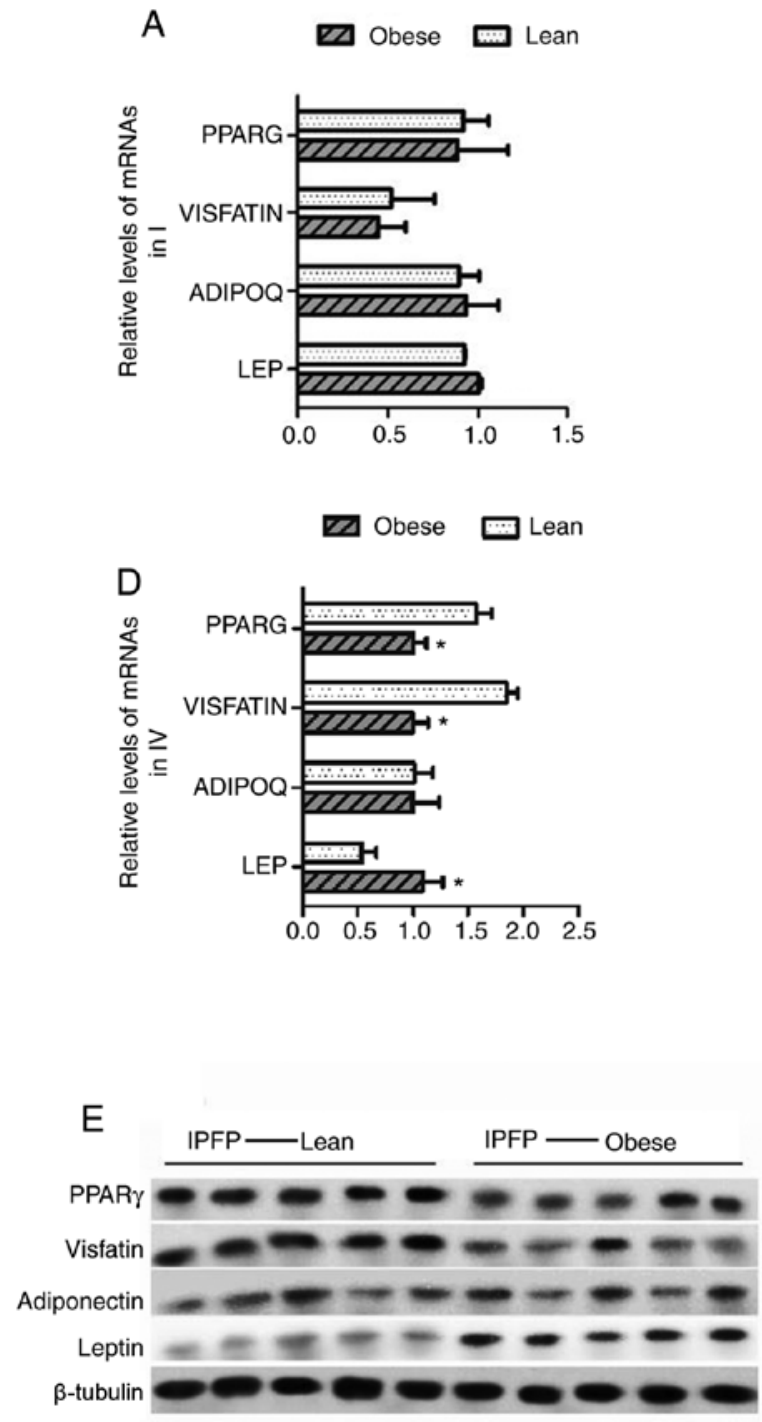
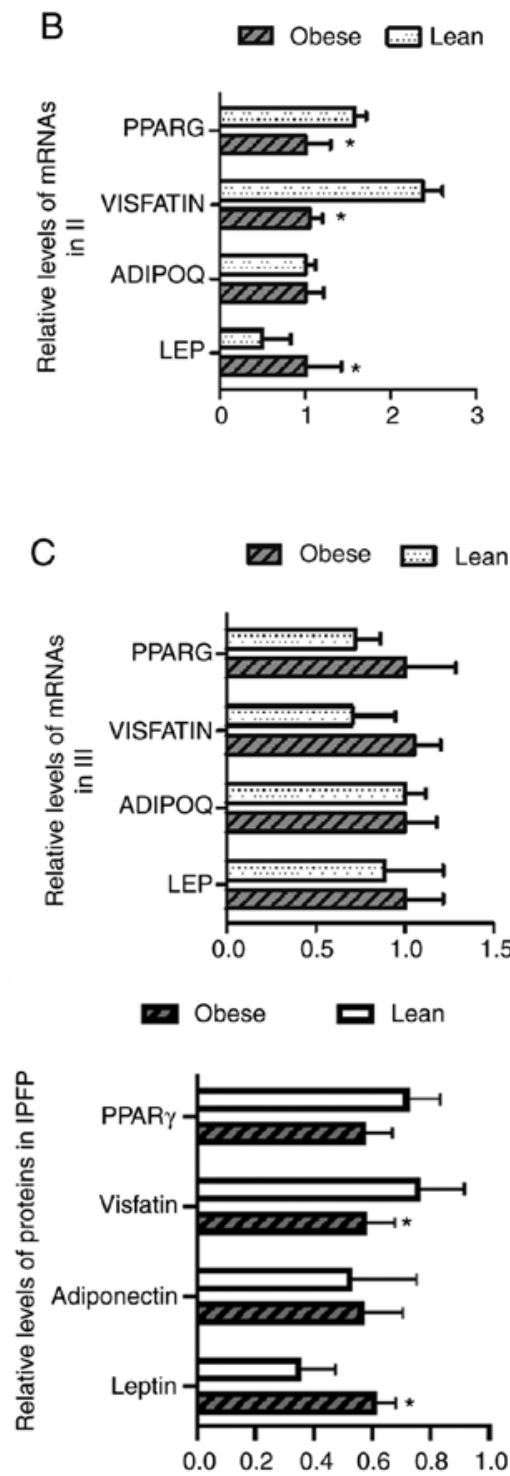

Figure 6. Differences in the expression of leptin, adiponectin, visfatin and PPAR $\gamma$ in adipose tissues from the knee joints of lean and obese patients with KOA. (A-D) The mRNA levels of leptin, adiponectin, visfatin and PPAR $\gamma$ were examined by RT-qPCR; "P $<0.05$ vs. I. (E) The protein levels of leptin, adiponectin, lisfatin and PPAR $\gamma$ were examined by western blot analysis; ${ }^{\mathrm{P}}<0.05$ vs. lean patients. KOA, knee osteoarthritis I, subcutaneous adipose tissue; II, IPFP near the synovial side; III, suprapatellar fat body; IV, near the patellar tendon side.

in a paracrine manner and affects cartilage, bone and synovial tissue inflammation $(15,32,33)$. By examining the changes in the expression levels of inflammatory factors in the IPFP tissues of obese and non-obese patients, the present study found that the expression levels of IL-6, IL- $1 \beta$ and TNF- $\alpha$ in the IPFPs of obese patients with KOA were higher than those in the IPFPs of non-obese patients, indicating that obese patients may be more susceptible to the destruction of cartilage matrix in bones and joints. Studies have demonstrated that IL-1 $\beta$, TNF- $\alpha$, IL-6, vascular endothelial growth factor (VEGF), leptin, adiponectin and other factors can be released in the IPFP $(16,17)$ and that these factors may exert marked effects on obesity-related diseases, including atherosclerosis and diabetes $(11,13)$.

The present study further explored the changes in the expression of adipocytokines in the IPFP tissues of obese and non-obese patients with KOA, and it was concluded that the expression of PPAR $\gamma$ and visfatin was downregulated in obese patients compared to non-obese patients, but that the expression of leptin increased with increasing weight. PPAR $\gamma$ is a key adipokinetic nuclear factor, and it has been demonstrated that pro-inflammatory cytokines, such as IL-1 $\beta$ and TNF- $\alpha$ can downregulate the expression of PPAR $\gamma$ in human chondrocytes (34). The expression of PPAR $\gamma$ in IPFP tissues has also been found to be lower than that in subcutaneous adipose tissue (16), which is consistent with the results of the present study. It was also found that the expression of PPAR $\gamma$ in the IPFP was downregulated in obese patients compared to non-obese patients, suggesting that PPAR $\gamma$ in the IPFP is related to the dysfunction of fat metabolism. Visfatin is considered to be involved in the pro-inflammatory process in OA, and the expression of visfatin is enhanced by IL-1 $\beta(35,36)$. Moreover, studies it has been previously found that visfatin-mediated inflammatory responses usually activate NF- $\mathrm{B}$ signaling (37). The results of the present study revealed reduced visfatin levels in obese patients with KOA compared with non-obese 
patients and suggested that visfatin plays an important role in inflammatory reactions, and tgat visfatin is regulated via diverse mechansims in obesity. Leptin is produced by fat cells in the IPFP and is reduced by $40 \%$ in normal IPFP tissues relative to subcutaneous adipose tissue (16). In patients with OA, leptin is released into the cartilage, the IPFP, the synovium and the callus, and normal non-OA cartilage produces less leptin than cartilage mildly affected by OA (38). Moreover, the findings of the present study demonstrated that leptin was highly expressed in the IPFP tissues of obese patients with KOA. Published results support these findings showing that the release of inflammatory cytokines, as well as leptin and adiponectin, is increased in the IPFPs of KOA patients cultured in vitro $(39,40)$. In addition, related studies have found that leptin (alone or in combination with IL-1 $\beta$ ) can increase the expression of IL-6, matrix metalloproteinase (MMP)-1, MMP-3 and MMP-13, which are involved in the regulation of the NF- $\kappa \mathrm{B}$ signaling pathway in the cartilage tissues of patients with OA (41). The present study also found a significant positive correlation between serum leptin levels and IL-6 levels in patients with KOA. All these findings reveal the key roles of the IPFP in the development of KOA in obese patients.

$\mathrm{NF}-\kappa \mathrm{B}$ is an important nuclear transcription factor that controls the expression and function of inflammatory genes. The regulation of $\mathrm{NF}-\kappa \mathrm{B}$-induced inflammatory factor-related changes in target gene levels can also trigger the activation of the $\mathrm{NF}-\kappa \mathrm{B}$ signaling pathway, which regulates the inflammatory response to a certain extent and has a long-lasting effect. The present study further investigated the activation of NF- $\kappa \mathrm{B}$ in IPFP tissues and it was found that IKK $\beta$, p65 and p-p65 were highly expressed and that their expression levels in obese patients with KOA were increased compared with those in non-obese patients. To the best of our knowledge, the activation of $\mathrm{NF}-\kappa \mathrm{B}$ in the IPFP tissues of obese patients with KOA has not yet been studied; however, the inflammatory cytokines and adipocytokines that were the focus of the present study have been reported to participate in the NF- $\kappa \mathrm{B}$ signaling pathway $(37,42,43)$. In addition, Hui et al reported that leptin induces the release of collagen, the expression of MMP-1 and MMP-13, and NF- $\kappa \mathrm{B}$ signaling activation in chondrocytes (44). These results suggest that $\mathrm{NF}-\kappa \mathrm{B}$ is activated in the IPFP tissues of obese patients with KOA and thus induces the expression of inflammation-related genes and regulates cartilage degeneration.

However, the small sample size and inevitable sample selection bias in the present study are limitations. Furthermore, the effect of environmental factors on KOA was not taken into account. Future studies with larger sample sizes are required to improve the accuracy of the assessments and to explore the sophisticated molecular regulatory mechanisms underlying the effects of obesity on KOA.

In conclusion, the present study suggests that the leptin levels in the synovia positively correlate with BMI. Moreover, obesity can cause differences in the expression of related inflammatory cytokines and adipocytokines in patients with $\mathrm{KOA}$, and can play a role in the development of KOA by triggering NF- $\mathrm{B}$ signaling in IPFP tissues.

\section{Acknowledgements}

Not applicable.

\section{Funding}

No funding was received.

\section{Availability of data and materials}

The datasets generated during and/or analyzed during the current study are available from the corresponding author upon reasonable request.

\section{Authors' contributions}

LD and XY conceived of and supervised the project. Tissue samples were collected by YWu. Experiments were conducted by LD, YM, YWa and JL. Data analyses were conducted by QW and ZT. LD wrote the manuscript and all authors contributed to the discussion and approved the final manuscript.

\section{Ethics approval and consent to participate}

The present study was approved by the Ethics Committee of Bayannaoer Hospital and was performed in accordance with the Helsinki Declaration. All participants signed informed consent forms for the extraction of knee joint fluid and the voluntary donation of IPFP specimens.

\section{Patient consent for publication}

Not applicable.

\section{Competing interests}

All authors declare that they have no competing interests.

\section{References}

1. Oliveria SA, Felson DT, Cirillo PA, Reed JI and Walker AM: Body weight, body mass index, and incident symptomatic osteoarthritis of the hand, hip, and knee. Epidemiology 10: 161-166, 1999.

2. Saltiel AR and Olefsky JM: Inflammatory mechanisms linking obesity and metabolic disease. J Clin Invest 127: 1-4, 2017.

3. Eymard $\mathrm{F}$ and Chevalier X: Inflammation of the infrapatellar fat pad. Joint Bone Spine 83: 389-393, 2016.

4. Griffin T: Biomechanical and metabolic implications of obesity in OA. Osteoarthritis Cartilage 26 (Suppl): S1, 2018.

5. Francisco V, Pérez T, Pino J, López V, Franco E, Alonso A, Gonzalez-Gay MA, Mera A, Lago F, Gómez R and Gualillo O: Biomechanics, obesity, and osteoarthritis. The role of adipokines: When the levee breaks. J Orthop Res 36: 595-604, 2018.

6. Van Beeck A, Clockaerts S, Somville J, Van Heeswijk JH, Van Glabbeek F, Bos PK and Reijman M: Does infrapatellar fat pad resection in total knee arthroplasty impair clinical outcome? A systematic review. Knee 20: 226-231, 2013.

7. Yoshimura N, Muraki S, Oka H, Tanaka S, Kawaguchi H, Nakamura $\mathrm{K}$ and Akune T: Accumulation of metabolic risk factors such as overweight, hypertension, dyslipidaemia, and impaired glucose tolerance raises the risk of occurrence and progression of knee osteoarthritis: A 3-year follow-up of the ROAD study. Osteoarthritis Cartilage 20: 1217-1226, 2012.

8. Kanneganti TD and Dixit VD: Immunological complications of obesity. Nat Immunol 13: 707-712, 2012.

9. Osborn $\mathrm{O}$ and Olefsky JM: The cellular and signaling networks linking the immune system and metabolism in disease. Nat Med 18: 363-374, 2012.

10. Buchholz AL, Niesen MC, Gausden EB, Sterken DG, Hetzel SJ, Baum SZ, Squire MW and Kaplan LD: Metabolic activity of osteoarthritic knees correlates with BMI. Knee 17: 161-166, 2010. 
11. Jotanovic Z, Mihelic R, Sestan B and Dembic Z: Role of interleukin-1 inhibitors in osteoarthritis: An evidence-based review. Drugs Aging 29: 343-358, 2012.

12. Guarner V and Rubio-Ruiz ME: Low-grade systemic inflammation connects aging, metabolic syndrome and cardiovascular disease. Interdiscip Top Gerontol 40: 99-106, 2015.

13. Dalmas E, Venteclef N, Caer C, Poitou C, Cremer I, Aron-Wisnewsky J, Lacroix-Desmazes S, Bayry J, Kaveri SV, Clément K, et al: T cell-derived IL-22 amplifies IL-1 $\beta$-driven inflammation in human adipose tissue: Relevance to obesity and type 2 diabetes. Diabetes 63: 1966-1977, 2014.

14. Esser N, Legrand-Poels S, Piette J, Scheen AJ and Paquot N: Inflammation as a link between obesity, metabolic syndrome and type 2 diabetes. Diabetes Res Clin Pract 105: 141-150, 2014.

15. Eymard F, Pigenet A, Citadelle D, Tordjman J, Foucher L, Rose C, Flouzat Lachaniette $\mathrm{CH}$, Rouault C, Clément K, Berenbaum F, et al: Knee and hip intra-articular adipose tissues (IAATs) compared with autologous subcutaneous adipose tissue: A specific phenotype for a central player in osteoarthritis. Ann Rheum Dis 76: 1142-1148, 2017.

16. Distel E, Cadoudal T, Durant S, Poignard A, Chevalier X and Benelli C: The infrapatellar fat pad in knee osteoarthritis: An important source of interleukin- 6 and its soluble receptor. Arthritis Rheum 60: 3374-3377, 2009.

17. Klein-Wieringa IR, Kloppenburg M,Bastiaansen-Jenniskens YM, Yusuf E, Kwekkeboom JC, El-Bannoudi H, Nelissen RG, Zuurmond A, Stojanovic-Susulic V, Van Osch GJ, et al: The infrapatellar fat pad of patients with osteoarthritis has an inflammatory phenotype. Ann Rheum Dis 70: 851-857, 2011

18. Eymard F, Pigenet A, Citadelle D, Flouzat-Lachaniette $\mathrm{CH}$, Poignard A, Benelli C, Berenbaum F, Chevalier X and Houard X: Induction of an inflammatory and prodegradative phenotype in autologous fibroblast-like synoviocytes by the infrapatellar fat pad from patients with knee osteoarthritis. Arthritis Rheumatol 66 2165-2174, 2014

19. Iwata M, Ochi H, Hara Y, Tagawa M, Koga D, Okawa A and Asou Y: Initial responses of articular tissues in a murine high-fat diet-induced osteoarthritis model: Pivotal role of the IPFP as a cytokine fountain. PLoS One 8: e60706, 2013.

20. Bastiaansen-Jenniskens YM, Wei W, Feijt C, Waarsing JH Verhaar JA, Zuurmond AM, Hanemaaijer R, Stoop R and van Osch GJ: Stimulation of fibrotic processes by the infrapatellar fat pad in cultured synoviocytes from patients with osteoarthritis: A possible role for prostaglandin f $2 \alpha$. Arthritis Rheum 65: 2070-2080, 2013.

21. Ma B and Hottiger MO: Crosstalk between Wnt/ $\beta$-catenin and NF- $\kappa \mathrm{B}$ signaling pathway during inflammation. Front Immunol 7: 378, 2016

22. Liao S, Zhou K, Li D, Xie X, Fang J and Wang J: Schisantherin A suppresses interleukin-1 $\beta$-induced inflammation in human chondrocytes via inhibition of NF- $\kappa \mathrm{B}$ and MAPKs activation. Eur J Pharmacol 780: 65-70, 2016

23. Olivotto E, Otero M, Marcu KB and Goldring MB: Pathophysiology of osteoarthritis: Canonical NF- $\mathrm{B} / \mathrm{IKK} \beta$-dependent and kinase-independent effects of IKK $\alpha$ in cartilage degradation and chondrocyte differentiation. RMD Open 1 (Suppl 1): e000061, 2015.

24. Livak KJ and Schmittgen TD: Analysis of relative gene expression data using real-time quantitative PCR and the 2(-Delta Delta C(T)) method. Methods 25: 402-408, 2001

25. Kulkarni K, Karssiens T, Kumar V and Pandit H: Obesity and osteoarthritis. Maturitas 89: 22-28, 2016

26. Jiang L, Rong J, Wang Y, Hu F, Bao C, Li X and Zhao Y: The relationship between body mass index and hip osteoarthritis: A systematic review and meta-analysis. Joint Bone Spine 78 : $150-155,2011$.

27. Jiang L, Tian W, Wang Y, Rong J, Bao C, Liu Y, Zhao Y and Wang C: Body mass index and susceptibility to knee osteoarthritis: A systematic review and meta-analysis. Joint Bone Spine 79: 291-297, 2012.

28. Wang X, Hunter D, Xu J and Ding C: Metabolic triggered inflammation in osteoarthritis. Osteoarthritis Cartilage 23: 22-30, 2015.
29. Apostolopoulos V, de Courten MP, Stojanovska L, Blatch GL, Tangalakis $\mathrm{K}$ and de Courten B: The complex immunological and inflammatory network of adipose tissue in obesity. Mol Nutr Food Res 60: 43-57, 2016

30. Iliopoulos D, Malizos KN, Oikonomou P and Tsezou A Integrative MicroRNA and proteomic approaches identify novel osteoarthritis genes and their collaborative metabolic and inflammatory networks. PLoS One 3: e3740, 2008.

31. Gandhi R, Takahashi M, Virtanen C, Syed K, Davey JR and Mahomed NN: Microarray analysis of the infrapatellar fat pad in knee osteoarthritis: Relationship with joint inflammation. J Rheumatol 38: 1966-1972, 2011.

32. Lübbeke A, Finckh A, Puskas GJ, Suva D, Lädermann A, Bas S, Fritschy D, Gabay C and Hoffmeyer P: Do synovial leptin levels correlate with pain in end stage arthritis? Int Orthopaedics 37: 2071-2079, 2013

33. Francisco V, Pino J, Gonzalez-Gay MA, Mera A, Lago F, Gómez R, Mobasheri A and Gualillo O: Adipokines and inflammation: Is it a question of weight? Br J Pharmacol 175: 1569-1579, 2018.

34. Afif H, Benderdour M, Mfuna-Endam L, Martel-Pelletier J, Pelletier JP, Duval N and Fahmi H: Peroxisome proliferator-activated receptor gamma 1 expression is diminished in human osteoarthritis cartilage and is downregulated by interleukin-1beta in articular chondrocytes. Arthritis Res Ther 9: R31, 2007.

35. Tu C, He J, Wu B, Wang W and Li Z: An extensive review regarding the adipokines in the pathogenesis and progression of osteoarthritis. Cytokine 113: 1-12, 2019.

36. Springer BD, Carter JT, McLawhorn AS, Scharf K, Roslin M, Kallies KJ, Morton JM and Kothari SN: Obesity and the role of bariatric surgery in the surgical management of osteoarthritis of the hip and knee: A review of the literature. Surg Obes Relat Dis 13: 111-118, 2017.

37. Lee WJ, Wu CS, Lin H, Lee IT, Wu CM, Tseng JJ, Chou MM and Sheu WH: Visfatin-induced expression of inflammatory mediators in human endothelial cells through the NF-kappaB pathway. Int J Obes (Lond) 33: 465-472, 2009.

38. Simopoulou T, Malizos K, Iliopoulos D, Stefanou N, Papatheodorou L, Ioannou M and Tsezou A: Differential expression of leptin and leptin's receptor isoform $(\mathrm{Ob}-\mathrm{Rb}) \mathrm{mRNA}$ between advanced and minimally affected osteoarthritic cartilage; effect on cartilage metabolism. Osteoarthritis Cartilage 15: 872-883, 2007.

39. Gross JB, Guillaume C, Gegout-Pottie P, Reboul P, Jouzeau JY, Mainard D and Presle N: The infrapatellar fat pad induces inflammatory and degradative effects in articular cells but not through leptin or adiponectin. Clin Exp Rheumatol 35: 53-60, 2017.

40. Kontny E, Plebanczyk M, Lisowska B, Olszewska M, Maldyk P and Maslinski W: Comparison of rheumatoid articular adipose and synovial tissue reactivity to proinflammatory stimuli: Contribution to adipocytokine network. Ann Rheum Dis 71: 262-267, 2012.

41. Koskinen A, Vuolteenaho K, Nieminen R, Moilanen T and Moilanen E: Leptin enhances MMP-1, MMP-3 and MMP-13 production in human osteoarthritic cartilage and correlates with MMP-1 and MMP-3 in synovial fluid from OA patients. Clin Exp Rheumatol 29: 57-64, 2011.

42. Zhang Y, Wang S, Zhu J, Li C, Zhang T, Liu H, Xu Q, Ye X, Zhou L and Ye L: Effect of atmospheric PM2.5 on expression levels of NF- $\kappa \mathrm{B}$ genes and inflammatory cytokines regulated by NF- $\kappa B$ in human macrophage. Inflammation 41: 784-794, 2018.

43. Li QY, Chen L, Yan MM, Shi XJ and Zhong MK: Tectorigenin regulates adipogenic differentiation and adipocytokines secretion via PPAR $\gamma$ and $I K K / N F-\kappa B$ signaling. Pharm Biol 53: $1567-1575,2015$.

44. Hui W, Litherland GJ, Elias MS, Kitson GI, Cawston TE, Rowan AD and Young DA: Leptin produced by joint white adipose tissue induces cartilage degradation via upregulation and activation of matrix metalloproteinases. Ann Rheum Dis 71: 455-462, 2012. 